\title{
Nitrous Oxide Use in Children
}

\author{
Leonardo Teixeira Domingues Duarte ${ }^{1}$, Gastão Fernandes Duval Neto ${ }^{2}$, Florentino Fernandes Mendes ${ }^{3}$
}

Summary: Duarte LTD, Duval Neto GF, Mendes FF - Nitrous Oxide Use in Children.

\section{DESCRIPTION OF THE EVIDENCE COLLECTION METHOD}

Searches were carried out in multiple databases (Medline 1965 to 2009, Cochrane Library, LILACS) and cross-references with the collected material to identify articles with better methodological design, followed by critical evaluation of their content and classification according with the strength of evidence.

Searches occurred between December 2007 and April 2008. The following search strategies were used for searches in PubMed:

1. Nitrous Oxide [MeSH] AND Pharmacology [MeSH] AND Toxicology [MeSH]

2. Nitrous Oxide [MeSH] AND Toxicology [MeSH]

3. Nitrous Oxide [MeSH] AND toxicity [subheading]

4. Nitrous Oxide [MeSH] AND Acute Toxicity Tests [MeSH] OR Toxicity Tests [MeSH]

5. Nitrous Oxide [MeSH] AND Drug Toxicity [MeSH] OR Toxic Actions [MeSH]

6. Nitrous Oxide [MeSH] AND Drug Interactions [MeSH]

7. Nitrous Oxide [MeSH] AND Food-Drug Interactions $[\mathrm{MeSH}]$

8. Nitrous Oxide [MeSH] AND Herb-Drug Interactions [MeSH]

9. Nitrous Oxide [MeSH] AND Anesthesia, General [MeSH] AND Postoperative Complications [MeSH] AND Randomized Controlled Tria[ptyp]

10. Nitrous Oxide [MeSH] AND Child [MeSH]

Received from the Brazilian Society of Anesthesiology (Sociedade Brasileira de Anestesiologia), Brazil.

1. MSc, Rehabilitation Sciences; Anesthesiologist, Hospital SARAH

2. PhD, Cardiovascular Surgery, Universidade Federal de São Paulo; Full Professor,

Anesthesiology, Departament of General Surgery, Faculdade de Medicina, Universidade

Federal de Pelotas (UFPel)

3. PhD, Surgery, Faculdade de Ciências Médicas da Santa Casa de São Paulo; Specialist in Pain Management, Universidade Federal do Rio Grande do Sul; Assistant Professor, Anesthesiology, Departament of Surgical Clinic, Universidade Federal de Ciências da Saúde

de Porto Alegre; Head of the Teaching and Training Center (CET), Universidade Federal de Ciências da Saúde de Porto Alegre

Correspondence to:

Sociedade Brasileira de Anestesiologia

Rua Professor Alfredo Gomes, 36

Botafogo

22251080 - Rio de Janeiro, RJ, Brazil

E-mail: rba@sba.com.br
11. Nitrous Oxide [MeSH] AND Anesthesia, General [MeSH] AND Child [MeSH] AND Randomized Controlled Trial[ptyp]

12. Pediatrics $[\mathrm{MeSH}]$ OR Neonatology [MeSH] AND Nitrous Oxide [MeSH]

13. Nitrous Oxide [MeSH] AND Anesthesia, General [MeSH] AND Pediatrics [MeSH] AND Randomized Controlled Tria[ptyp]

14. Nitrous Oxide [MeSH] AND Anesthesia, General [MeSH] AND Neonatology [MeSH] AND Randomized Controlled Tria[ptyp]

15. Cerebral Palsy [MeSH] AND Child [MeSH] AND Nitrous Oxide [MeSH]

Studies comparing different classes of anesthetic drugs or sedation techniques in children undergoing diagnostic tests or procedures with the use of sedation or anesthesia were selected. Also selected were studies that evaluated the pharmacological effects of nitrous oxide, its interaction with other anesthetics and its toxic effects in children.

\section{DEGREE OF RECOMMENDATION AND STRENGTH OF EVIDENCE}

A: Experimental or observational studies of best consistency.

B: Experimental or observational studies of least consistency.

C: Case Reports (non-controlled studies).

D: Opinion without critical evaluation, based on consensuses, physiological studies or animal models.

\section{OBJECTIVE}

To evaluate the advantages and disadvantages of nitrous oxide administration in different procedures requiring sedation and analgesia, as well as its safety in children.

\section{INTRODUCTION}

The inhaled anesthetic nitrous oxide is an inorganic compound, odorless, with a linear and simple structure, which at room temperature and pressure, is in the gas phase and is 
chemically stable. The action mechanism of nitrous oxide is still poorly known, but certainly involves several types of receptors including the dopaminergic and $\alpha 2$-adrenergic receptors, benzodiazepines and N-methyl D-aspartate (NMDA).

Nitrous oxide has low anesthetic potency. It needs to be inhaled at a pressure close to $0.7 \mathrm{Atm}(530 \mathrm{~mm} \mathrm{Hg})$ to result in unconsciousness in $50 \%$ of patients and above 1 Atm to prevent muscular movement during nociceptive stimulation of the skin incision. Due to this pharmacodynamic characteristic, nitrous oxide is usually used in combination with intravenous or inhaled anesthetics.

Notwithstanding the criticism and warnings expressed in the literature about the safety of its clinical use, the use of nitrous oxide in anesthesia is common worldwide. The main factors that justify this situation are its well-defined indications for clinical use ${ }^{1}(D)$. Furthermore, nitrous oxide is very well tolerated by pediatric patients, making it possible to perform mild anesthesia induction with a mask. The rapid onset of action and brief resolution of the effect, in addition to the absence of nephrotoxicity or hepatotoxicity and contraindication for use in patients susceptible to malignant hyperthermia, are other features that make nitrous oxide an attractive option in pediatric anesthesia ${ }^{1}(\mathrm{D})$.

\section{INTERACTION WITH OTHER ANESTHETIC AGENTS}

\section{Inhaled Anesthetics}

\section{What are the effects of the combination of volatile anesthetics and nitrous oxide?}

Nitrous oxide can accelerate the time of induction of inhalational anesthesia. The addition of high concentrations of nitrous oxide to a mixture of gases accelerates the partial pressure increase of volatile anesthetic at the end of expiration, as well as of their partial arterial pressure ${ }^{2}(B)$. The presence of high concentrations of nitrous oxide has an effect of concentration and second gas, facilitating the pure inhalation induction by mask, especially in pediatric anesthesia. The second gas effect will be even more significant with nitrous oxide, the lower the solubility of the associated volatile anesthetic. Nitrous oxide enhances alveolar uptake of the second gas in anesthesia induction or when there is an increase of its fraction inhaled during the procedure ${ }^{3}(\mathrm{~B})$.

The addition of high concentrations of nitrous oxide to sevoflurane during anesthesia induction in children promotes acceleration of the balance between the alveolar and inhaled concentrations of the volatile anesthetic agent ${ }^{4}(\mathrm{D})$. The addition of nitrous oxide to high concentrations of sevoflurane results in a faster loss of consciousness ${ }^{5}(\mathrm{~B})$. The combination of nitrous oxide at $70 \%$ and enflurane determines a decrease in the time of induction and awakening from anesthesia, and a lower incidence of airway problems during intubation and respiratory depression $\left(\mathrm{P}_{\mathrm{et}} \mathrm{CO}_{2}\right.$ and apnea ${ }^{6}(\mathrm{~B})$. On the other hand, the addition of nitrous oxide at $50 \%$ in anesthesia induction with sevoflurane is associated with increased occurrence of excitatory phenomena ${ }^{7}(\mathrm{~B})$.
Anesthesia induction with sevoflurane at $8 \%$ promotes similar anesthetic conditions and occurrence of adverse events, regardless of the combination with nitrous oxide at $60 \%{ }^{8}(\mathrm{~B})$. There is no difference in blood pressure levels, heart rate and pulse oximetry, as well as the occurrence of limb movement during venipuncture and adverse events. Likewise, the induction time, the position of the vocal cords in tracheal intubation and conditions for intubation, as well as the emergence time are similar regardless of the nitrous oxide combination ${ }^{9}(A)$. There is also no difference in the maintenance of anesthesia with sevoflurane when nitrous oxide was omitted from the anesthetic technique ${ }^{10}(\mathrm{~A})$.

There is no difference in opioid consumption, time to extubation and reorientation, the quality of awakening and postoperative analgesia and the occurrence of nausea and vomiting after surgery if nitrous oxide is combined with sevoflurane ${ }^{10}(A)$. The time and conditions for tracheal intubation are similar, despite the combination of nitrous oxide, which is not associated with a higher occurrence of respiratory complications, even in children with obstructive airways undergoing tonsillectomy ${ }^{5}(\mathrm{~B})$.

Most data in the literature indicate additive interaction between nitrous oxide and volatile anesthetics in order to reduce the minimum alveolar concentration (MAC) of these anesthetics in adults and children. Nitrous oxide has an additive contribution to halothane, as increasing concentrations of nitrous oxide are combined, thus reducing its MAC linearly ${ }^{11}(\mathrm{~B})$. Nitrous oxide also reduces the MAC of sevoflurane for laryngeal mask insertion in children, in a linear and additive way ${ }^{12}(A)$, promoting this effect to prevent movement during laryngoscopy and tracheal intubation ${ }^{13}(A)$. Administration of nitrous oxide at $33 \%$ and $66 \%$ linearly decreases sevoflurane MAC in $18 \%$ and $40 \%$ during laryngoscopy and intubation, respectively.

From this sparing effect of sevoflurane, together with the knowledge that the administration of high concentrations of sevoflurane may determine an epileptogenic effect, it is suggested that the combination of nitrous oxide can reduce the risk of occurrence of epileptiform tracings in electroencephalograms of children during sevoflurane administration ${ }^{14}(\mathrm{D})$.

The MAC of desflurane is reduced by $25 \%$ with concomitant administration of nitrous oxide ${ }^{15}(\mathrm{~B})$ and the MAC of isoflurane in children also decreases linearly with the administration of increasing concentrations of nitrous oxide ${ }^{16}(\mathrm{~B})$.

Recommendations: In spite of its low anesthetic potency, when combined with other inhalation anesthetics and at an inhaled concentration of $60 \%$ to $70 \%$ in oxygen, nitrous oxide accelerates the time of anesthesia induction (especially with poorly soluble volatile anesthetics) ${ }^{5,6}(B)$, significantly reduces the need for the latter ${ }^{12}(\mathrm{a}){ }^{11,15,16}(\mathrm{~B})$ and allows reducing the exposure of patients and health professionals to potentially toxic anesthetic gases and vapors. On the other hand, it does not seem to alter the anesthetic conditions caused by volatile agents ${ }^{9,10}(A)$ and emergence time, when combined with a low solubility agent such as sevoflurane ${ }^{10}(A)$. Moreover, it can favor the occurrence of excitatory phenomena associated with sevoflurane ${ }^{7}(B)$. 
Intravenous anesthetic agents

\section{What are the types of interactions that can occur between nitrous oxide and intravenous anesthetics?}

The combination of nitrous oxide with target-controlled infusion of propofol allows a $25 \%$ decrease in the mean plasma concentration of propofol necessary to prevent response to the surgical incision ${ }^{17}(\mathrm{~B})$. Equally, inhalation of nitrous oxide at $66 \%$ before anesthesia induction with propofol allows a $44 \%$ decrease in the required dose of hypnotic drug for the loss of response to verbal commands and the time of anesthesia induction ${ }^{18}(\mathrm{~A})$.

The administration of nitrous oxide to children sedated with moderate doses of chloral hydrate and hydroxyzine, when compared to oxygen administration, results in less crying and more pacific behavior, with no potentiation of the pharmacological effects on parameters such as heart rate, blood pressure, peripheral oxygen saturation and expired $\mathrm{CO}_{2}{ }^{19}(\mathrm{~B})$. The addition of nitrous oxide at $30 \%$ or $50 \%$ in children sedated with chloral hydrate and submitted to dental procedures depresses ventilation and often results in deep sedation ${ }^{20}(\mathrm{~B})$.

There is an overlap of the effects of opioids and nitrous oxide, so that the latter reduces the sparing effect of opioids on the MAC of volatile anesthetics in rats ${ }^{21,22}(D)$. When fentanyl is administered in a sufficient dose, the subsequent addition of nitrous oxide to the volatile anesthetic causes no additional reduction in $\mathrm{MAC}^{23}(\mathrm{~B})$. On the other hand, apparently conflicting results occur when the opioid remifentanil is administered. The decreased MAC of sevoflurane promoted by the administration of nitrous oxide at $60 \%$ during a target-controlled infusion of remifentanil $1 \mathrm{ng} \cdot \mathrm{mL}^{-1}$ also occurs when the infusion is increased to $3 \mathrm{ng} \cdot \mathrm{mL}^{-1}{ }^{24}(\mathrm{~A})$. It is possible that the difference in results is due to different mechanisms of action of fentanyl and remifentanil on the NMDA receptor. While remifentanil activates the NMDA receptor, nitrous oxide as NMDA antagonist can block the activating effect of the opioid and maintain the sparing effect on the MAC.

Recommendations: The combination of nitrous oxide usually produces additive interaction with propofol for the time of anesthesia induction ${ }^{18}(A)$ and sedatives ${ }^{19}(B)$. On the other hand, there appears to be no additive interaction with opioids ${ }^{23}(B)$, except when the agent used is remifentanil ${ }^{24}(A)$.

\section{Hemodynamic effects}

\section{What are the hemodynamic effects secondary to the addition of nitrous oxide?}

In adults, the combination of $65 \%$ nitrous oxide with isoflurane or sevoflurane causes less hypotension that the administration of the same volatile anesthetic alone at proportionally equivalent concentrations ${ }^{25}(B)$. Due to the depressant effects of volatile anesthetics, the sparing effect determined by the combination of nitrous oxide can lead to lower cardiovascular and respiratory depression, and less interaction with other drugs ${ }^{25}(\mathrm{~B})$. Moreover, the addition of nitrous oxide at $70 \%$ to increasing plasma concentrations of propofol does not alter the blood pressure up to when the target concentration of propofol is $>5 \mu \mathrm{g} \cdot \mathrm{mL}^{-1} 26(\mathrm{~B})$.

Contrary to what occurs in adults, the addition of nitrous oxide to anesthesia with 1 MAC of halothane or isoflurane in children does not result in cardiovascular signs secondary to sympathetic stimulation ${ }^{27}(\mathrm{~B})$. Actually, the addition of nitrous oxide causes a decrease in heart rate, mean arterial pressure and consequent reduction in cardiac output. Systolic volume and ejection fraction do not change with the addition of nitrous oxide.

Recommendations: The combination of nitrous oxide and volatile anesthetic agents reduces the incidence of hypotension when compared to the administration of these agents alone, at equipotent doses ${ }^{25}(\mathrm{~B})$. On the other hand, the combination of nitrous oxide with halothane or isoflurane at a dose of $1 \mathrm{MAC}$ in children cause decreased cardiac output ${ }^{27}(\mathrm{~B})$.

\section{Respiratory effects}

\section{What are the respiratory effects of nitrous oxide use in children?}

The respiratory effects produced by nitrous oxide in children differ according to the associated volatile anesthetic. While the depressant effect with halothane is similar when combined with nitrous oxide at $50 \%$ or pure oxygen during anesthesia with enflurane, the combination of nitrous oxide determines a lower depressant effect ${ }^{28}(\mathrm{~B})$.

The state of oxygenation before tracheal intubation in children is crucial for the time interval until the onset of arterial desaturation. Thus, the lower inspired oxygen fraction associated with the inclusion of nitrous oxide in the inhaled gas mixture determines a faster decrease in oxygen saturation in hemoglobin ${ }^{29}(\mathrm{~B})$. On the other hand, the intraoperative use of nitrous oxide at $66 \%$ does not influence the occurrence of desaturation episodes during emergence from anesthesia in children ${ }^{30}(A)$. The use of air instead of nitrous oxide, in order to reduce the formation of atelectasis is not supported in the literature.

Recommendations: The intensity of the depressant effect of nitrous oxide on ventilation, when combined with volatile anesthetic agents, differs depending on the halogenated agent ${ }^{28}(\mathrm{~B})$. The combination of nitrous oxide determines faster arterial desaturation during tracheal intubation ${ }^{29}(B)$, but does not alter its occurrence at emergence from anesthesia ${ }^{30}(A)$.

\section{Effects on the brain}

\section{What effects does nitrous oxide have on the child's brain?}

The addition of nitrous oxide does not affect the reactivity of the brain vasculature to $\mathrm{CO}_{2}$ during anesthesia with propofol in children ${ }^{31}(\mathrm{~B})$. When brain vascular reactivity must be pre- 
served, the combination of propofol and nitrous oxide is an appropriate alternative ${ }^{31}(\mathrm{~B})$. Nitrous oxide at $65 \%$ promotes an increase of about $12 \%$ in the speed of cerebral blood flow during target-controlled anesthesia with propofol at $3 \mu \mathrm{g} \cdot \mathrm{mL}^{-1}$ in children. The effect of nitrous oxide on the rate of cerebral blood flow is maintained during the infusion of propofol, while its replacement by air implies in a reduction of about $14 \%$ in the rate of cerebral blood flow ${ }^{32}(\mathrm{~B})$.

In the anesthesia with sevoflurane at 1.5 MAC, the addition of nitrous oxide causes a decrease in cerebrovascular reactivity to $\mathrm{CO}_{2}$ during hypocapnia (fraction of expired $\mathrm{CO} 2$ between 25 and $35 \mathrm{~mm} \mathrm{Hg}{ }^{33}(\mathrm{~B})$. This effect will be important when hyperventilation is considered to reduce the brain volume in children with intracranial hypertension ${ }^{33}(\mathrm{~B})$. The addition of nitrous oxide to sevoflurane at 1 MAC promotes an increase in cerebral blood flow velocity, which returns to baseline after nitrous oxide withdrawal ${ }^{34}(\mathrm{~B})$. In contrast, in the anesthesia with 1 MAC of desflurane, the addition of nitrous oxide does not alter the speed of cerebral blood flow ${ }^{35}(B)$.

Recommendation: The effects of nitrous oxide on children's cerebral hemodynamics differ according to the combined anesthetic. When combined with propofol, there is little change in cerebral reactivity ${ }^{31}(\mathrm{~B})$, whereas the combination with volatile agents determines the greatest change with lower cerebrovascular reactivity during hypocapnia ${ }^{31}(\mathrm{~B})$.

\section{Role of nitrous oxide as sedation and analgesia technique}

\section{Is the use of Nitrous Oxide a safe sedation and analgesia technique in children?}

There are few data in the literature regarding the safety of nitrous oxide use as sedation and analgesia technique in children. Regarding the depth of sedation and incidence of adverse effects associated with inhalation of nitrous oxide in children ${ }^{36}(\mathrm{~B})$, it is known that high concentrations of the gas $(70 \%)$ result in mild to moderate sedation with low occurrence of adverse effects, and that they safe for sedation and analgesia even in children under three years of age ${ }^{36}(B)$. The occurrence of adverse effects - mostly vomiting - does not differ between the administration of nitrous oxide at $50 \%$ or $70 \%$.

Recommendation: The degree of sedation induced by nitrous oxide in children is mild and has a low frequency of adverse effects, which are mostly vomiting ${ }^{36}(B)$.

\section{Is the use of Nitrous Oxide an effective sedation and analgesia technique in children?}

Nitrous oxide can be used as a method of sedation and analgesia in children in several clinical situations, alone or in combination with other analgesic techniques, such as analgesic drugs, eutectic mixture of local anesthetics (EMLA) and lidocaine infiltration ${ }^{37}(\mathrm{~B})$.

Children may present considerable pain and anxiety when undergoing surgical procedures or painful diagnostic tests. Minor surgical procedures in children (lumbar punctures, bone marrow aspiration, sutures, venipuncture, correction of fractures, dental and endoscopic procedures) require effective pain, anxiety and movement control. The administration of nitrous oxide at concentrations below $50 \%$ is an effective alternative to conscious sedation and general anesthesia in minor pediatric surgical procedures. The technique provides great relief from pain and anxiety, satisfaction of parents, patients and assistant staff, maintains protective reflexes and does not require monitoring after the procedure ${ }^{38}(\mathrm{D})$.

\section{Dental procedures}

Over $90 \%$ of children undergoing dental extractions successfully complete the treatment under sedation with nitrous oxide at $30 \%{ }^{39}(B)$ and inhalation sedation with this same gas is effective in children of different ages, especially older children who require orthodontic treatment, or even four dental extractions ${ }^{40}(\mathrm{D})$. On the other hand when compared to general anesthesia, inhalation sedation demands longer time periods per case and a higher number of treatment sessions per patient.

Inhalation of nitrous oxide at $50 \%$ by healthy children is referred to as pleasant experience, but it determines significant effects on psychomotor capacity ${ }^{41}(C)$. Sedation with nitrous oxide at $30 \%$ is superior to the administration of intravenous ${ }^{42}(B)$ or transmucosal ${ }^{43}(B)$ midazolam (maximum dose of $5 \mathrm{mg}$ ) in children between 10 and 16 years of age undergoing dental extractions. While the techniques are equivalent in terms of efficacy and safety, nitrous oxide is associated, however, with shorter times to achieve the maximum level of sedation and recovery ${ }^{42,43}(\mathrm{~B})$. Furthermore, the compliance with the inhalation technique is greater than with the transmucosal route due to the unpleasant taste of midazolam ${ }^{43}(B)$.

Inhalation of nitrous oxide is an alternative technique to control pain and anxiety in dental procedures and has proven to be reliable in relation to general anesthesia. In fact, the administration of nitrous oxide alone, or combined with sevoflurane at low concentration $(0.1 \%$ to $0.3 \%)$ does not cause complications and allows children to remain aware and responsive to verbal commands during the dental treatment and in the recovery room ${ }^{44}(A)$.

The combination of nitrous oxide sedation with behavioral techniques and distractions (e.g., videogame) help in the management of anxiety in children undergoing dental treatment. The combination of non-pharmacological and pharmacological methods of sedation promotes proper sedation and increases the child's compliance by decreasing the excitation and fear ${ }^{45}(\mathrm{C})$.

Recommendations: The inhaled sedation with nitrous oxide is well indicated in the dental care of older children and when fewer than four extractions are necessary ${ }^{40}(D)$. When 
administered by qualified professionals using appropriate equipment, it is considered a technique with a high rate of success ${ }^{39}(\mathrm{~B})$ and low occurrence of side effects and complications, so it can be an effective and safe alternative to general anesthesia ${ }^{44}(\mathrm{~A})$. However, in most cases, analgesia provided by nitrous oxide is not sufficient to provide a painless dental treatment and supplementation with a local anesthetic is required ${ }^{40}(\mathrm{D})$.

\section{Bone fracture reduction}

The success rate and intensity of pain are similar in children who require nonsurgical management of forearm fractures, when techniques for analgesia are inhaled nitrous oxide or intravenous regional anesthesia. Analgesia with nitrous oxide allows the procedure to be completed more quickly ${ }^{46}(\mathrm{~B})$, although we cannot conclude on the efficacy of nitrous oxide as a technique for sedation and analgesia in children undergoing fracture reductions ${ }^{47}(A)$.

Recommendations: There are insufficient data to indicate or contraindicate the use of nitrous oxide in children undergoing fracture reductions.

\section{Otorhinolaryngological procedures}

Otoscopic examination and other procedures are uncomfortable and as a consequence of pain and anxiety, children may not cooperate with the examiner. Inhalation of nitrous oxide for sedation and analgesia during the examination and minor otologic surgical procedures in small, non-cooperative children are useful and effective methods for pain relief ${ }^{48}(C)$.

Recommendation: Inhalation of nitrous oxide is effective in relieving the discomfort of otological procedures in children ${ }^{48}(\mathrm{C})$.

\section{Urological procedures}

Sedation with nitrous oxide is effective in reducing anxiety and pain during catheterization for urethrocystography in children and adolescents between 4 and 18 years of age ${ }^{49}(B)$. The administration of nitrous oxide does not cause serious adverse events (apnea and arterial desaturation below 92\%), and the incidence of mild adverse events (diaphoresis, nausea, vomiting) is low, occurring in $4 \%$ of patients ${ }^{50}(\mathrm{~B})$.

When compared with oral midazolam, inhalation of nitrous oxide at $50 \%$ is equally effective and safe in relieving pain and anxiety associated with urethrocystography in children older than 3 years of age ${ }^{51}(A)$. However, nitrous oxide allows a more rapid onset of sedation and a shorter recovery.

Recommendation: Sedation with nitrous oxide can reduce the anxiety related to catheterization for urethrocystography ${ }^{49,50}(\mathrm{~B})$ and its efficacy is similar to oral sedation with midazolam ${ }^{51}(A)$.

\section{Skin sutures}

The administration of nitrous oxide at $50 \%$ in children undergoing repair of skin lacerations allows the reduction of pain and anxiety scores ${ }^{52}(\mathrm{~B})$. The use of nitrous oxide is also superior to oral midazolam in the suturing of lacerations of the face, by promoting lower pain scores during wound care and local anesthetic injection, in addition to promoting faster recovery and fewer adverse effects in children between 2 and 6 years of age ${ }^{53}(A)$.

Recommendation: The administration of nitrous oxide is effective and superior to oral midazolam for sedation when performing skin sutures in children ${ }^{53}(A)$.

\section{Venipuncture}

The administration of nitrous oxide at $50 \%$ or $70 \%$ is effective for reducing pain and anxiety associated with venipuncture in children. The use of higher concentrations, however, is associated with increased frequency of adverse events ${ }^{54}(B)$. The combination of inhalation of nitrous oxide at $50 \%$ and eutectic mixture of local anesthetics (lidocaine and prilocaine) is effective for the insertion of central venous catheters in children and has limited side effects (euphoria 14\%, deep sedation $4 \%$, nausea and vomiting $2 \%$ and hallucinations $2 \%$ ) ${ }^{55}(\mathrm{~B})$.

The combined therapy with nitrous oxide at $50 \%$ and EMLA is superior to either of the two treatments alone for venous cannulation, and is associated with lower pain scores in children aged between 8 and 15 years. On the other hand there is no difference when both techniques are used separately ${ }^{56}(A)$. The pain relief produced by inhalation of nitrous oxide at $70 \%$ in children between 6 and 11 years of age, the technical simplicity and efficiency are similar to those produced by the use of EMLA ${ }^{57}(B)$. On the other hand, there is also evidence that the inhaled nitric oxide at $70 \%$ is superior to the use of EMLA, resulting in lower pain scores during venous cannulation ${ }^{58}(A)$.

Recommendations: Nitrous oxide inhalation was found to be effective in relieving the pain associated with venipuncture in children ${ }^{54}(\mathrm{~B})$. However, the results are superior when combined with the use of EMLA (lidocaine and prilocaine) ${ }^{56}(A)$.

\section{Injections}

The administration of nitrous oxide at $50 \%$, combined with local use of EMLA, is associated with lower pain scores during and immediately after intramuscular injection in children, and is superior to the separate administration of each strategy ${ }^{59}(A)$. Furthermore, inhalation of nitrous oxide at $50 \%$, prior to intravenous administration of propofol, reduces the pain associated with injection in children, when compared to the inhalation of $100 \%$ oxygen ${ }^{60}(A)$. In children with cerebral 
palsy submitted to injection of botulinum toxin $A$, sedation promoted by the inhalation of nitrous oxide is more effective than midazolam administered by the enteral route ${ }^{61}(A)$.

Recommendation: The administration of nitrous oxide, alone or in combination with EMLA is associated with effective sedation and pain relief in children receiving injections ${ }^{59-61}(A)$.

\section{Others}

The administration of nitrous oxide at $50 \%$ and oxygen combined with local topical anesthesia is safe and effective in sedation and relief of pain and anxiety in children undergoing fiber optic bronchoscopy ${ }^{62}(\mathrm{~A})$.

The administration of nitrous oxide promotes rapid and effective analgesia without heavy sedation and with minimal adverse effects in children undergoing upper endoscopy ${ }^{63}(\mathrm{~B})$. It allows cooperation, and a rapid and adequate examination.

There are no benefits with the use of intravenous morphine or nitrous oxide in children undergoing chest tube removal. There is no difference in the analgesic efficacy of two techniques, which are also not effective in pain relief when used as a single technique ${ }^{64}(\mathrm{~A})$.

\section{ADVERSE EFFECTS}

\section{Postoperative Nausea and Vomiting}

Postoperative nausea and vomiting are among the most common adverse events related to anesthesia and surgery. Their incidence, however, varies depending on the risk profile of the patient and the surgery, as well as the prophylactic measures used ${ }^{65}(\mathrm{D})$.

The probability of occurrence of nausea and vomiting in the recovery room after anesthesia is 2.24 times higher when nitrous oxide is used in adults ${ }^{66}(\mathrm{~B})$. Similarly, independent risk factors are identified for postoperative nausea and vomiting, among which is the administration of nitrous oxide ${ }^{67}(\mathrm{D})$, which is also a predictor of nausea and vomiting in patients older than 18 years of age undergoing surgery lasting more than 2 hours ${ }^{68}(\mathrm{~A})$. The omission of nitrous oxide may decrease the incidence of symptoms in almost $30 \%$, while the impact of the strategy is linked to patients at high risk for the occurrence of postoperative nausea and vomiting

On the other hand, the addition of nitrous oxide at $70 \%$ to sevoflurane ${ }^{69}(A)$ or halothane ${ }^{70}(A)$ is not associated with increased frequency of postoperative nausea and vomiting in children. Similarly, the severity and incidence of vomiting in children did not differ between patients treated with nitrous oxide at $70 \%$ and those who did not receive the anesthetic ${ }^{71}(\mathrm{~A})$. On the contrary, when combined with propofol, nitrous oxide is associated with increased incidence of postoperative vomiting ${ }^{72}(\mathrm{~A})$.
Recommendations: Nitrous oxide does not appear to increase the occurrence of postoperative nausea and vomiting in children when combined with volatile anesthetics ${ }^{69,70}(A)$. Moreover, the known protective effect of propofol against nausea and vomiting may be lost when it is associated with nitrous oxide ${ }^{72}(A)$.

\section{TOXIC EFFECTS}

\section{Toxicology}

There has been clinical evidence of the toxic effects of nitrous oxide for about 50 years, with potential alterations in the health of exposed patients, as well as in the occupational health of healthcare professionals exposed to chronic inhalation (environmental) of this anesthetic ${ }^{73}(\mathrm{D})$.

Anesthesia with nitrous oxide in rats rapidly inhibited the activity of methionine synthase ${ }^{74}(\mathrm{D})$ and their exposure for 2 hours was associated with a $50 \%$ reduction in the activity of methionine synthase ${ }^{75}(\mathrm{D})$. The exposure to nitrous oxide at $50 \%$ decreased the activity of the enzyme after 30 minutes, being undetectable after 6 hours. Also in rats, the administration at $50 \%$ for one hour reduced enzyme activity to $11 \%$ and $18 \%$ in both maternal and fetal livers, respectively ${ }^{76}(\mathrm{D})$. Extrapolating these findings to humans should be done carefully, as rats are more sensitive to the inhibitory action of nitrous oxide than humans ${ }^{77}(\mathrm{C})$. Commonly, enzyme activity is recovered 2-4 days after exposure to nitrous oxide ${ }^{74}(\mathrm{D})$.

The inhibition of the methionine synthase enzyme by nitrous oxide occurs through the oxidation of the cobalt ion $\left(\mathrm{Co}^{+}\right)$of its coenzyme - cobalamin $\left(\mathrm{B}_{12} \text { vitamin }\right)^{74}(\mathrm{D})$. With the oxidized cobalt cation, $B_{12}$ vitamin is prevented from acting as a coenzyme of methionine synthase. In addition to the $B_{12}$ vitamin, methionine synthase also requires 5-methyltetrahydrofolate as a coenzyme, with a crucial role in the biosynthesis of purines and pyrimidines and the metabolism of serine and glycine, which donate methyl groups to cobalamin, forming methylcobalamin, the final donor of methyl groups in the conversion of homocysteine to methionine.

The actual clinical consequences of these biological and pharmacological activities, however, are not yet fully understood. One suggests that the possible alterations secondary to its administration can be expressed as deleterious immunological, hematological, neurological, myocardial, reproductive and infectious effects, among others. The use of nitrous oxide in a prolonged or repeated manner can result in megaloblastic anemia and/or subacute degeneration of the spinal $\operatorname{cord}^{1}(D)$.

Recommendations: Given the importance of methionine synthase for cell function, due to its contribution to the generation of methyl groups for the synthesis of DNA, RNA, myelin, catecholamines, among others, the interference imposed by nitrous oxide on the metabolism of $B_{12}$ vitamin and folate demands caution in the case of pediatric patients with known $B_{12}$ vitamin deficiency (genetic or environmental) or report of 
this vitamin deficiency ${ }^{1}(D)$. These patients should be recognized in order to determine the need for monitoring these metabolic alterations in the perioperative period.

\section{Neurodegeneration}

As a NMDA receptor antagonist, nitrous oxide can promote both neuroprotective actions (against neurodegenerative alterations caused by NMDA agonists) and neurotoxic ones, depending on the circumstances ${ }^{78}(\mathrm{D})$. Another hypothesized mechanism for the neurotoxicity triggered by nitrous oxide is the interference with dopamine release mechanisms ${ }^{79}(D)$. While these findings raise concern about the administration of nitrous oxide in combination with other NMDA antagonists, the risk of neurotoxicity should decrease when its administration is combined with other general anesthetics that exert a GABAergic effect and minimize the possible neurotoxicity of nitrous oxide ${ }^{78}(\mathrm{D})$.

Evidence from animal studies has shown that nitrous oxide may be deleterious to the brain during child development and may be a potential risk to some premature patients and newborns ${ }^{80}(\mathrm{D})$. Studies have suggested that nitrous oxide has neurotoxic effects on immature rat brains by a mechanism involving apoptosis induction, either independently or in combination, enhancing the activity of halogenated anesthetics ${ }^{80}(D)$. Although the exposure to nitrous oxide at $75 \%$ did not induce apoptotic degeneration in neonatal rat brain, nitrous oxide exacerbates the injury caused by isoflurane ${ }^{80}(\mathrm{D})$. The combination of nitrous oxide and isoflurane with midazolam administered for 6 hours to young rats caused extensive apoptotic neurodegeneration, as well as memory and learning disorders ${ }^{81}(\mathrm{D})$.

However, in this and other studies, administration of nitrous oxide alone did not cause increased apoptosis. Furthermore, the study results may represent, when applied to humans, prolonged exposure such as sedation in the intensive care unit, much higher than that during surgical procedures.

Recommendations: Although studies suggest that nitrous oxide has neurotoxic effects on immature brains, the current evidence of injury is insufficient to contraindicate its use in children. There is no current evidence that its use will adversely affect the neurological development of children ${ }^{80,81}(\mathrm{D})$.

\section{Hematological and neurological complications}

Patients with $B_{12}$ vitamin deficiency (secondary to resection of the terminal ileum, pernicious anemia or dietary restrictions - vegetarians and those on protein-restriction diets) are at increased risk of developing complications secondary to the metabolic effects of nitrous oxide. Case reports illustrate that these patients or newborns of mothers with these problems may present hematological and neurological complications after exposure to nitrous oxide ${ }^{82}$ (D) ${ }^{83,84}(\mathrm{C})$.

Patients with vitamin $B_{12}$ deficiency developed different hematological and neurological manifestations, after intraoperative exposure to nitrous oxide ${ }^{82}$ (D) ${ }^{83,84}(\mathrm{C})$. Thus, various authors raise the concern about the administration of nitrous oxide to children, given the high prevalence of metabolic defects and vitamin deficiencies in this population.

The inhibition of the methionine synthase enzyme can cause megaloblastic anemia ${ }^{85}(\mathrm{D})$. Patients with deficiency of cobalamin or folate would be particularly at higher risk. Short periods of nitric oxide inhalation (2-6 hours) may result in megaloblastic alterations in the bone marrow of patients with severely impaired health due to dysfunction in methionine and DNA synthesis ${ }^{86}(\mathrm{C})$. After 24 hours of exposure hyperpigmented neutrophils appear, as well as megaloblastic alterations and acute failure of bone marrow activity.

In patients with latent $B_{12}$ vitamin deficiency, myeloneuropatias, spastic paresthesia, acute funicular myeloid failure and psychiatric manifestations can be seen after exposure to nitrous oxide ${ }^{87}(\mathrm{C})$. While the occurrence of neurological lesion is unlikely with a short-term exposure to nitrous oxide (as in a single surgical procedure), the reduction of methionine synthase activity after repeated exposures caused myelinopathy with medullar degeneration in humans ${ }^{87}(\mathrm{C})$ and animals ${ }^{88}(\mathrm{D})$. Neurological lesions have also been described after anesthesia with nitrous oxide in patient with cobala$\min { }^{89}(\mathrm{C})$ or folate ${ }^{90}(\mathrm{~A})$ deficiency.

The fatal outcome was described in a child aged 3 months with a diagnosis of Type III homocystinuria (5,10-methylenetetrahydrofolate reductase enzyme defect), exposed to nitrous oxide twice in a period of four days ${ }^{89}(\mathrm{C})$.

It has been presumed that the combination of genetic defect with the inhibition of the methionine synthase enzyme - induced by nitrous oxide - was fatal ${ }^{89}(\mathrm{C})$. Other polymorphisms of the 5,10-methylenetetrahydrofolate reductase enzyme are more common. The literature also has reports of myelopathy and macrocytic anemia responsive to folate and $B_{12}$ vitamin after two exposures to nitrous oxide within a 10-day period ${ }^{91}(\mathrm{C})$. Subsequent evaluation showed elevated levels of homocysteine, low $\mathrm{B}^{12}$ vitamin levels and gene mutation of the methylenetetrahydrofolate reductase enzyme ${ }^{91}(C)$.

Recommendations: The effects of nitrous oxide on vitamin $\mathrm{B}_{12}$-dependent pathways in patients with deficiency of the methionine synthase enzyme are not known, but it seems reasonable to avoid its use in children with deficiency of this enzyme, as well as other $B_{12}$ vitamin metabolism defects ${ }^{83,84,86,87,89}(\mathrm{C}){ }^{90}(\mathrm{~A})$. 
10. Rocca G, Montecchi C, Baisi F, Monaco S, Romboli D, Gasparetto A - N2O-free sevoflurane anesthesia. Clinical evaluation. Minerva Anestesiol, 2000;66:611-9.(A)

11. Murray DJ, Mehta MP, Forbes RB, Dull DL - Additive contribution of nitrous oxide to halothane MAC in infants and children. Anesth Analg, 1990;71:120-124. (B)

12. Kihara $S$, Yaguchi $Y$, Inomata $S$ et al. - Influence of nitrous oxide on minimum alveolar concentration of sevoflurane for laryngeal mask insertion in children. Anesthesiology, 2003;99:1055-1058.(A)

13. Swan HD, Crawford MW, Pua HL, Stephens D, Lerman J - Additive contribution of nitrous oxide to sevoflurane minimum alveolar concentration for tracheal intubation in children. Anesthesiology, 1999;91:667-671.(A)

14. Bordes $M$, Cros $A M$ - Inhalation induction with sevoflurane in paediatrics: what is new? Ann Fr Anesth Reanim, 2006;25:413-416.(D)

15. Fisher DM, Zwass MS - MAC of desflurane in $60 \%$ nitrous oxide in infants and children. Anesthesiology, 1992;76:354-356.(B)

16. Murray DJ, Mehta MP, Forbes RB - The additive contribution of nitrous oxide to isoflurane MAC in infants and children. Anesthesiology, 1991;75:186-190.(B)

17. Davidson JA, Macleod AD, Howie JC, White M, Kenny GN - Effective concentration 50 for propofol with and without $67 \%$ nitrous oxide. Acta Anaesthesiol Scand, 1993;37:458-464.(B)

18. $\mathrm{Ng} \mathrm{JM}$, Hwang $\mathrm{NC}$ - Inhaling nitrous oxide reduces the induction dose requirements of propofol. Anesth Analg, 2000;90:1213-1216.(A)

19. McCann W, Wilson S, Larsen P, Stehle B - The effects of nitrous oxide on behavior and physiological parameters during conscious sedation with a moderate dose of chloral hydrate and hydroxyzine. Pediatr Dent, 1996;18:35-41.(B)

20. Litman RS, Kottra JA, Verga KA, Berkowitz RJ, Ward DS - Chloral hydrate sedation: the additive sedative and respiratory depressant effects of nitrous oxide. Anesth Analg, 1998;86:724-728.(B)

21. Sawamura S, Obara M, Takeda K, Maze M, Hanaoka K - Corticotropin-releasing factor mediates the antinociceptive action of nitrous oxide in rats. Anesthesiology, 2003;99:708-715.(D)

22. Santos M, Kuncar V, Martinez-Taboada F, Tendillo FJ - Large concentrations of nitrous oxide decrease the isoflurane minimum alveolar concentration sparing effect of morphine in the rat. Anesth Analg, 2005;100:404-408.(D)

\section{REFERÊNCIAS/REFERENCES}

1. Myles PS, Leslie K, Silbert B, Paech M, Peyton P - A review of the risks and benefits of nitrous oxide in current anaesthetic practice. Anaesth Intensive Care, 2004;32:165-172. (D)

2. Peyton PJ, Horriat M, Robinson GJ, Pierce R, Thompson BR - Magnitude of the second gas effect on arterial sevoflurane partial pressure. Anesthesiology, 2008;108:381-387.(B)

3. Tunstall ME, Hawksworth GM - Halothane uptake and nitrous oxide concentration. Arterial halothane levels during Caesarean section. Anaesthesia, 1981;36:177-182. (B)

4. Goldman LJ - Anesthetic uptake of sevoflurane and nitrous oxide during an inhaled induction in children. Anesth Analg, 2003;96:400-406. (D)

5. Dubois MC, Piat V, Constant I, Lamblin O, Murat I - Comparison of three techniques for induction of anaesthesia with sevoflurane in children. Paediatr Anaesth, 1999;9:19-23.(B)

6. Sigurdsson $\mathrm{GH}$ - Respiratory depression during enflurane anaesthesia in children: influence of the nitrous oxide concentration. Eur $J$ Anaesthesiol, 1986;3:87-94.(B)

7. O'Shea H, Moultrie S, Drummond GB - Influence of nitrous oxide on induction of anaesthesia with sevoflurane. Br J Anaesth, 2001;87:286288.(B)

8. Fernandez-Alcantud J, Sanabria Carretero P, Rodriguez Pérez E, Planas Roca $A$ - Anesthetic induction with nitrous-oxide-free sevoflurane in pediatric patients. Rev Esp Anestesiol Reanim, 2008;55:69-74.(B)

9. Sarner JB, Levine M, Davis PJ, Lerman J, Cook DR, Motoyama EK Clinical characteristics of sevoflurane in children. A comparison with halothane. Anesthesiology, 1995;82:38-46.(A)

23. Ghouri AF, White PF - Effect of fentanyl and nitrous oxide on the desflurane anesthetic requirement. Anesth Analg, 1991;72:377-781.(B)

24. Albertin A, Casati A, Bergonzi P, Fano G, Torri G - Effects of two target-controlled concentrations (1 and $3 \mathrm{ng} / \mathrm{ml}$ ) of remifentanil on MAC(BAR) of sevoflurane. Anesthesiology, 2004;100:255-259.(A)

25. Inada T, Inada K, Kawachi S, Takubo K, Tai M, Yasugi $\mathrm{H}$ - Haemodynamic comparison of sevoflurane and isoflurane anaesthesia in surgical patients. Can J Anaesth, 1997;44:140-145.(B)

26. Shiga T, Wajima Z, Inoue T, Ogawa R - Nitrous oxide produces minimal hemodynamic changes in patients receiving a propofol-based anesthetic: an esophageal Doppler ultrasound study. Can J Anaesth, 2003;50:649-652.(B)

27. Murray DJ, Forbes RB, Dull DL, Mahoney LT - Hemodynamic responses to nitrous oxide during inhalation anesthesia in pediatric patients. J Clin Anesth, 1991;3:14-19.(B)

28. Murat I, Le BF, Chaussain M, Saint-Maurice C - Respiratory effects of nitrous oxide during halothane or enflurane anaesthesia in children. Acta Anaesthesiol Scand, 1988;32:186-192.(B)

29. Kinouchi K, Fukumitsu K, Tashiro C, Takauchi Y, Ohashi Y, Nishida $\mathrm{T}$ - Duration of apnoea in anaesthetized children required for desaturation of haemoglobin to $95 \%$ : comparison of three different breathing gases. Paediatr Anaesth, 1995;5:115-119.(B)

30. Elwood T, Hutchinson E-Oxygen in nitrogen versus nitrous oxide during pediatric general anesthesia. Acta Anaesthesiol Sin, 2001;39:5964.(A)

31. Karsli C, Wilson-Smith E, Luginbuehl I, Bissonnette B - The effect of nitrous oxide on cerebrovascular reactivity to carbon dioxide in children during propofol anesthesia. Anesth Analg, 2003;97:694-698.(B)

32. Wilson-Smith E, Karsli C, Luginbuehl IA, Bissonnette B - The effect of nitrous oxide on cerebral blood flow velocity in children anesthetized with propofol. Acta Anaesthesiol Scand, 2003;47:307-311.(B) 
33. Wilson-Smith E, Karsli C, Luginbuehl I, Bissonnette B - Effect of nitrous oxide on cerebrovascular reactivity to carbon dioxide in children during sevoflurane anaesthesia. Br J Anaesth, 2003;91:190-195.(B)

34. Rowney DA, Fairgrieve R, Bissonnette $B$ - The effect of nitrous oxide on cerebral blood flow velocity in children anaesthetised with sevoflurane. Anaesthesia, 2004;59:10-14.(B)

35. Karsli C, Luginbuehl IA, Bissonnette B - The effect of nitrous oxide on cerebral blood flow velocity in children anaesthetised with desflurane. Anaesthesia, 2003;58:24-27.(B)

36. Babl FE, Oakley E, Seaman C, Barnett P, Sharwood LN - High-concentration nitrous oxide for procedural sedation in children: adverse events and depth of sedation. Pediatrics, 2008;121:e528-e532.(B)

37. Annequin D, Carbajal R, Chauvin P, Gall O, Tourniaire B, Murat I Fixed $50 \%$ nitrous oxide oxygen mixture for painful procedures: A French survey. Pediatrics, 2000;105:E47.(B)

38. Burnweit C, Diana-Zerpa JA, Nahmad MH et al. - Nitrous oxide analgesia for minor pediatric surgical procedures: an effective alternative to conscious sedation? J Pediatr Surg, 2004;39:495-499.(D)

39. Foley $\mathrm{J}-\mathrm{A}$ prospective study of the use of nitrous oxide inhalation sedation for dental treatment in anxious children. Eur J Paediatr Dent, 2005;6:121-128.(B)

40. Lyratzopoulos G, Blain KM - Inhalation sedation with nitrous oxide as an alternative to dental general anaesthesia for children. J Public Health Med, 2003;25:303-312.(D)

41. Houpt MI, Limb R, Livingston RL - Clinical effects of nitrous oxide conscious sedation in children. Pediatr Dent, 2004;26:29-36.(C)

42. Wilson KE, Girdler NM, Welbury RR - Randomized, controlled, crossover clinical trial comparing intravenous midazolam sedation with nitrous oxide sedation in children undergoing dental extractions. $\mathrm{Br} \mathrm{J}$ Anaesth, 2003;91:850-856.(B)

43. Wilson KE, Welbury RR, Girdler NM - Comparison of transmucosal midazolam with inhalation sedation for dental extractions in children. A randomized, cross-over, clinical trial. Acta Anaesthesiol Scand, 2007;51:1062-1067.(B)

44. Lahoud GY, Averley PA - Comparison of sevoflurane and nitrous oxide mixture with nitrous oxide alone for inhalation conscious sedation in children having dental treatment: a randomised controlled trial. Anaesthesia, 2002;57:446-450.(A)

45. Denman WT, Tuason PM, Ahmed MI, Brennen LM, Cepeda MS, Carr DB - The PediSedate device, a novel approach to pediatric sedation that provides distraction and inhaled nitrous oxide: clinical evaluation in a large case series. Paediatr Anaesth, 2007;17:162-166.(C)

46. Gregory PR, Sullivan JA. Nitrous oxide compared with intravenous regional anesthesia in pediatric forearm fracture manipulation. J Pediatr Orthop, 1996;16:187-191.(B)

47. Migita RT, Klein EJ, Garrison MM - Sedation and analgesia for pediatric fracture reduction in the emergency department: a systematic review. Arch Pediatr Adolesc Med, 2006;160:46-51.(A)

48. Fishman G, Botzer E, Marouani N, DeRowe A - Nitrous oxide-oxygen inhalation for outpatient otologic examination and minor procedures performed on the uncooperative child. Int J Pediatr Otorhinolaryngol, 2005;69:501-504.(C)

49. Zier JL, Kvam KA, Kurachek SC, Finkelstein M - Sedation with nitrous oxide compared with no sedation during catheterization for urologic imaging in children. Pediatr Radiol, 2007;37:678-684.(B)

50. Zier JL, Drake GJ, McCormick PC, Clinch KM, Cornfield DN - Caseseries of nurse-administered nitrous oxide for urinary catheterization in children. Anesth Analg, 2007;104:876-879.(B)

51. Keidan I, Zaslansky $\mathrm{R}$, Weinberg $\mathrm{M}$ et al. - Sedation during voiding cystourethrography: comparison of the efficacy and safety of using oral midazolam and continuous flow nitrous oxide. J Urol, 2005;174:15981600.(A)

52. Burton $\mathrm{JH}$, Auble TE, Fuchs $\mathrm{SM}$ - Effectiveness of $50 \%$ nitrous oxide/ $50 \%$ oxygen during laceration repair in children. Acad Emerg Med, 1998;5:112-117.(B)

53. Luhmann JD, Kennedy RM, Porter FL, Miller JP, Jaffe DM - A randomized clinical trial of continuous-flow nitrous oxide and midazolam for sedation of young children during laceration repair. Ann Emerg Med, 2001;37:20-27.(A)
54. Henderson JM, Spence DG, Komocar LM, Bonn GE, Stenstrom RJ Administration of nitrous oxide to pediatric patients provides analgesia for venous cannulation. Anesthesiology, 1990;72:269-271.(B)

55. Abdelkefi A, Abdennebi YB, Mellouli $F$ et al. - Effectiveness of fixed $50 \%$ nitrous oxide oxygen mixture and EMLA cream for insertion of central venous catheters in children. Pediatr Blood Cancer, 2004;43:777-779.(B)

56. Hee HI, Goy RW, Ng AS - Effective reduction of anxiety and pain during venous cannulation in children: a comparison of analgesic efficacy conferred by nitrous oxide, EMLA and combination. Paediatr Anaesth, 2003;13:210-216.(A)

57. Paut O, Calmejane C, Delorme J, Lacroix F, Camboulives J - EMLA versus nitrous oxide for venous cannulation in children. Anesth Analg, 2001;93:590-593.(B)

58. Vetter TR - A comparison of EMLA cream versus nitrous oxide for pediatric venous cannulation. J Clin Anesth, 1995;7:486-490.(A)

59. Carbajal R, Biran V, Lenclen R et al. - EMLA cream and nitrous oxide to alleviate pain induced by palivizumab (Synagis) intramuscular injections in infants and young children. Pediatrics, 2008;121:e1591e1598.(A)

60. Beh T, Splinter W, Kim J - In children, nitrous oxide decreases pain on injection of propofol mixed with lidocaine. Can J Anaesth, 2002;49:1061-1063.(A)

61. Zier JL, Rivard PF, Krach LE, Wendorf HR - Effectiveness of sedation using nitrous oxide compared with enteral midazolam for botulinum toxin A injections in children. Dev Med Child Neurol, 2008;50:854-858. (A)

62. Fauroux B, Onody P, Gall O, Tourniaire B, Koscielny S, Clément A The efficacy of premixed nitrous oxide and oxygen for fiberoptic bronchoscopy in pediatric patients: a randomized, double-blind, controlled study. Chest, 2004;125:315-321.(A)

63. Michaud L, Gottrand F, Ganga-Zandzou PS et al. - Nitrous oxide sedation in pediatric patients undergoing gastrointestinal endoscopy. $J$ Pediatr Gastroenterol Nutr, 1999;28:310-314.(B)

64. Bruce E, Franck L, Howard RF - The efficacy of morphine and Entonox analgesia during chest drain removal in children. Paediatr Anaesth, 2006;16:302-308.(A)

65. Kovac $A L$ - Prevention and treatment of postoperative nausea and vomiting. Drugs, 2000;59:213-243.(D)

66. Junger A, Hartmann B, Benson M - The use of an anesthesia information management system for prediction of antiemetic rescue treatment at the postanesthesia care unit. Anesth Analg, 2001;92:1203-1209. (B)

67. Gan T - Risk Factors for Postoperative Nausea and Vomiting. Anesth Analg, 2006;102:1884-1898.(D)

68. Leslie K, Myles P, Chan M; ENIGMA Trial Group - Risk factors for severe postoperative nausea and vomiting in a randomized trial of nitrous oxide-based $v s$ nitrous oxide-free anaesthesia. $\mathrm{Br} \mathrm{J}$ Anaesth, 2008;101:498-505.(A)

69. Bortone L, Picetti E, Mergoni M - Anaesthesia with sevoflurane in children: nitrous oxide does not increase postoperative vomiting. Paediatr Anaesth, 2002;12:775-779.(A)

70. Splinter WM, Komocar $L-$ Nitrous oxide does not increase vomiting after dental restorations in children. Anesth Analg, 1997;84:506-508. (A)

71. Pandit UA, Malviya S, Lewis IH - Vomiting after outpatient tonsillectomy and adenoidectomy in children: the role of nitrous oxide. Anesth Analg, 1995;80:230-233.(A)

72. Crawford MW, Lerman J, Sloan MH, Sikich N, Halpern L, Bissonnette B - Recovery characteristics of propofol anaesthesia, with and without nitrous oxide: a comparison with halothane/nitrous oxide anaesthesia in children. Paediatr Anaesth, 1998;8:49-54.(A)

73. Linde HW, Bruce DL - Occupational exposure of anesthetists to halothane, nitrous oxide and radiation. Anesthesiology, 1969;30:363-8.(D)

74. Deacon R, Lumb M, Perry J et al. Inactivation of methionine synthase by nitrous oxide. Eur J Biochem, 1980;104:419-23.(D)

75. Nunn JF - Clinical aspects of the interaction between nitrous oxide and vitamin B12. Br J Anaesth, 1987;59:3-13.(D)

76. Baden JM, Serra M, Mazze RI - Inhibition of fetal methionine synthase by nitrous oxide. Br J Anaesth, 1984;56:523-526.(D) 
77. Royston BD, Nunn JF, Weinbren HK, Royston D, Cormack RS - Rate of inactivation of human and rodent hepatic methionine synthase by nitrous oxide. Anesthesiology, 1988;68:213-216.(C)

78. Jevtovic-Todorovic V, Todorovic SM, Mennerick S et al. - Nitrous oxide (laughing gas) is an NMDA antagonist, neuroprotectant and neurotoxin. Nat Med, 1998;4:460-463.(D)

79. Sakamoto S, Nakao S, Masuzawa M et al. - The differential effects of nitrous oxide and xenon on extracellular dopamine levels in the rat nucleus accumbens: a microdialysis study. Anesth Analg, 2006;103:1459-1463.(D)

80. Jevtovic-Todorovic V, Hartman RE, Izumi $Y$ et al. - Early exposure to common anesthetic agents causes widespread neurodegeneration in the developing rat brain and persistent learning deficits. J Neurosci, 2003;23:876-882.(D)

81. Ma $D$, Williamson $P$, Januszewski $A$ et al. - Xenon mitigates isoflurane-induced neuronal apoptosis in the developing rodent brain. Anesthesiology, 2007;106:746-753.(D)

82. Felmet K, Robins B, Tilford D, Hayflick SJ - Acute neurologic decompensation in an infant with cobalamin deficiency exposed to nitrous oxide. J Pediatr, 2000;137:427-428.(D)

83. McNeely JK, Buczulinski B, Rosner DR - Severe neurological impairment in an infant after nitrous oxide anesthesia. Anesthesiology, 2000;93:1549-1550.(C)

84. Rosener M, Dichgans J - Severe combined degeneration of the spinal cord after nitrous oxide anaesthesia in a vegetarian. J Neurol Neurosurg Psychiatry, 1996;60:354.(C)

85. Reynolds E - Vitamin B12, folic acid, and the nervous system. Lancet Neurol, 2006;5:949-960.(D)

86. Amos RJ, Hinds CJ, Amess JA, Molin DL - Incidence and pathogenesis of acute megaloblastic bone-marrow change in patients receiving intensive care. Lancet, 1982;2:835-838.(C)

87. Doran M, Rassam SS, Jones LM, Underhill S - Toxicity after intermittent inhalation of nitrous oxide for analgesia. BMJ, 2004;328:13641365.(C)

88. Weir DG, Keating S, Molloy A et al. - Methylation deficiency causes vitamin B12-associated neuropathy in the pig. J Neurochem, 1988;51:1949-1952.(D)

89. Selzer RR, Rosenblatt DS, Laxova R, Hogan K - Adverse effect of nitrous oxide in a child with 5,10-methylenetetrahydrofolate reductase deficiency. N Engl J Med, 2003;349:45-50.(C)

90. Deleu D, Louon A, Sivagnanam S et al. - Long-term effects of nitrous oxide anaesthesia on laboratory and clinical parameters in elderly Omani patients: a randomized double-blind study. J Clin Pharm Ther, 2000;25:271-277.(A)

91. Lacassie HJ, Nazar C, Yonish B, Sandoval P, Muir HA, Mellado P Reversible nitrous oxide myelopathy and a polymorphism in the gene encoding 5,10-methylenetetrahydrofolate reductase. $\mathrm{Br} J$ Anaesth, 2006;96:222-225.(C) 